\title{
Governança das ações e serviços de saúde de média complexidade em uma região de saúde
}

\author{
Governance of medium complexity health actions and services in a \\ health region
}

Carolina Milena Domingos', Edinalva de Moura Ferraz', Brígida Gimenez Carvalho'

DOI: $10.1590 / 0103-1104201912204$

RESUMO O estudo objetivou analisar atores e suas relações, espaços e desafios enfrentados na governança das ações e serviços de saúde de média complexidade em uma região de saúde. Estudo qualitativo, desenvolvido por meio de entrevistas com gestores públicos de saúde, um representante do Gestor Estadual de Saúde, o apoiador regional do Paraná e o diretor do Consórcio Intermunicipal de Saúde. Os resultados permitiram classificar os atores em governamentais e de mercado. As reuniões das comissões intergestores regionais foram ressaltadas como possíveis espaços para a governança das ações e serviços de saúde de média complexidade. Entre os desafios, estão: a falta de solidariedade e compartilhamento de responsabilidades entre os entes federativos; a fragilidade do ente municipal, em relação aos demais atores envolvidos na governança; a interferência política de deputados, junto ao Gestor Estadual. A governança das ações e serviços de saúde de média complexidade se apresenta como um grande jogo, permeado por relações de competição e conflitos.

PALAVRAS-CHAVE Governança. Regionalização. Atenção secundária à saúde.

ABSTRACT The study aimed to analyze actors and their relationships, spaces and challenges faced in the governance of actions and services of medium complexity health in a health region. A qualitative study, developed through interviews with public health managers, a representative of the State Health Manager, the regional supporter of Parana and the director of the Intermunicipal Health Consortium. The results allowed to classify the actors in government and market. The meetings of the regional interagency commissions were highlighted as possible spaces for actions and services of medium complexity health governance. Among the challenges, are: the lack of solidarity and sharing of responsibilities between federative entities; the fragility of the municipal entity, in relation to the other actors involved in governance; the political interference of deputies, with the State Manager. Actions and services of medium complexity health governance presents itself as a great game, permeated by competitive relationships and conflicts.

KEYWORDS Governance. Regional health planning. Secondary care.

1 Universidade Estadual de Londrina (UEL) - Londrina (PR), Brasil.

carolinamdomingos@gmail. com 


\section{Introdução}

Entre as diretrizes do Sistema Único de Saúde (SUS), encontra-se a regionalização, que pode ser percebida como um processo técnico-político, abrangendo a distribuição de poder, as relações estabelecidas entre governos, as organizações públicas e privadas e os cidadãos, entre outros, em um determinado espaço geográfico ${ }^{\mathbf{1}, 2}$.

No âmbito da regionalização, apresentam-se diversos indivíduos como partes do processo de negociação que caracteriza a governança regional. Esta, compreendendo o exercício do poder, refere-se aos processos de governo, à reorientação das formas de relação entre estado e sociedade, entre governos, e entre agentes privados e sociedade ${ }^{3}$.

A governança representa diversidades de interesses organizados e negociados de acordo com finalidades comuns na garantia do direito à saúde. Para o seu desenvolvimento, destaca-se a criação de um ambiente institucional favorável à coordenação e articulação de atores, serviços e ações ${ }^{4}$. Ela também constitui um dos componentes e elemento-chave para a organização das Redes de Atenção em Saúde (RAS).

Na constituição das RAS, as Ações e Serviços de Média Complexidade (ASMC) têm representado um problema de grande relevância, seja no campo da gestão ou no campo da assistência, constituindo-se em um desafio para a organização da atenção em saúde 5 . As ASMC visam atender às demandas de saúde e agravos da população, cuja prática clínica dependa de profissionais especializados e uso de recursos tecnológicos de apoio diagnóstico e terapêutico ${ }^{6}$.

Para superar esses obstáculos, observa-se a necessidade de fortalecer a região de saúde, viabilizando políticas de saúde coerentes com a necessidade coletiva. Todavia, conforme destacam Ribeiro, Tanaka e Denis ${ }^{7}$, ao visualizar a região como lócus político-social, observa-se que a mesma é arraigada por assimetrias, conflitos de poder e contradições.

Essas assimetrias e incongruências também podem ser visualizadas nas arenas de articulação federativa, conforme identificado por Nicoletto ${ }^{8}$, causando desconforto entre os atores que participam destes cenários. Dourado e Elias 9 apontam que, para a gestão de políticas públicas em federações, torna-se imprescindível a construção de processos decisórios compartilhados no planejamento e na execução das ações, em âmbito socioeconômico, que visem o bem-estar coletivo.

Essa coordenação federativa pode ser realizada com regras transparentes e legais, que levem os atores a dividirem as decisões e tarefas, bem como a definirem suas competências no âmbito das políticas públicas ${ }^{10}$. A articulação entre os entes federativos na rede deve ser pautada por princípios jurídicos administrativos, capazes de propiciar a integração e cogestão dos serviços de saúde, em que ocorra a interdependência política administrativa e financeira -, sem hierarquia, mantendo a autonomia de cada ente ${ }^{\mathbf{1 1}}$.

Para o alcance desse patamar, é preciso desenvolver mecanismos de comunicação entre os atores governamentais envolvidos nos cenários de cogestão, fortalecendo a lógica da governança federativa. A qualificação dos gestores do SUS, no âmbito regional, para que exerçam de maneira mais efetiva o poder que lhes cabe, exige o desenvolvimento de processos político-negociais capazes de aumentar a identificação de necessidades, a construção de objetivos comuns e a afirmação de políticas regionais e locais convergentes e compatíveis com as distintas realidades municipais ${ }^{7}$.

Diante desse contexto, este estudo tem como objetivo analisar os espaços, os atores e suas relações, e os desafios enfrentados na governança ASMC, em uma região de saúde.

\section{Material e métodos}

Trata-se de um estudo qualitativo, exploratório, desenvolvido na área de abrangência de uma regional de saúde, composta por 17 municípios, situada no norte do estado do Paraná. Os dados foram obtidos por meio de 
oito entrevistas semiestruturadas, orientadas a partir de um roteiro, realizadas no período de novembro de 2016 a maio de 2017.

A população de estudo foi constituída por cinco gestores públicos de saúde, ocupantes do cargo de secretários municipais de saúde, representantes de municípios de diferentes portes populacionais (um de município com menos de 5 mil; um de município entre 5 mil e 10 mil; um de município entre 10 mil e 25 mil; e dois de municípios com mais de 100 mil habitantes) e de diferentes responsabilidades assumidas pela gestão (da atenção básica e do sistema municipal de saúde). Foram selecionados a partir de indicação dos representantes da regional de saúde, considerando o destaque de sua assiduidade e atuação nas reuniões da Comissão Intergestores Regional (CIR).

Participaram, ainda, um representante do Gestor Estadual do SUS (representante da Secretaria Estadual de Saúde na CIR), o apoiador regional do Conselho de Secretários Municipais de Saúde do Paraná (Cosems-PR) e a diretora do Consórcio Intermunicipal de Saúde do Vale do Ivaí e Região (Cisvir). As entrevistas foram transcritas na íntegra, e os participantes foram identificados por códigos, recebendo a letra E seguida de um número, conforme a ordem de realização - primeira, E1; última, E8.

Os dados foram organizados e examinados por meio da análise de discurso proposta por Martins e Bicudo ${ }^{12}$. Em seguida, utilizou-se a contribuição teórica do Jogo Social, de Carlos Matus ${ }^{13}$, para um maior aprofundamento analítico dos resultados. Para este autor, o jogo social é composto de vários outros jogos, com destaque para três: o econômico, o da comunicação e o macro-organizacional. O jogo econômico liberta ou subjuga o homem através da satisfação das necessidades econômicas. No jogo da comunicação, se estabelece a disputa pela transparência, opacidade e controle da interação humana, e se utiliza da linguagem como poder de comunicação. O jogo macro-organizacional produz a ação organizacional, ou seja, visa materializar a produção institucional e se coloca a serviço de qualquer um dos outros jogos na luta pela distribuição de governança e de poder organizacional.

Nessa perspectiva, adotou-se esse referencial devido ao fato de o cenário da gestão federativa ser permeado por vários jogos sociais e pela complexidade existente nos espaços em que se dão as relações entre os atores envolvidos no processo de governança ${ }^{13}$.

O presente estudo integra um projeto maior, denominado 'Gestão interfederativa do SUS na organização de arranjos regionais para atenção de média complexidade na macrorregião norte do Paraná'. As normas relativas a pesquisas que envolvem seres humanos foram respeitadas, conforme Resolução ${ }^{\circ}$ 466/2012 ${ }^{14}$ do Conselho Nacional de Saúde. O presente estudo foi submetido e aprovado pelo Comitê de Ética em Pesquisa da Universidade em que estão inseridas as pesquisadoras, sob o parecer número 1700851, de 29 de agosto de 2016.

\section{Resultados e discussão}

O processo de análise das entrevistas resultou na proposição de duas categorias: atores, suas relações e espaços envolvidos no processo de governança das ASMC; e os desafios enfrentados na região para governança das ASMC. Ambas serão apresentadas a seguir.

\section{Atores, suas relações e espaços en- volvidos no processo de governança das ASMC}

O conjunto do material analisado permitiu classificar, com base em Cortes ${ }^{\mathbf{1 5}}$, os atores que participam do processo de governança da média complexidade, em atores governamentais e atores de mercado. Os governamentais são os sujeitos que participam dos cenários de negociação federativa. Entre eles, podem ser citados: os da esfera municipal - representados pelos secretários municipais de saúde e os prefeitos; os de âmbito estadual - representados pelos funcionários da Secretaria Estadual de 
Saúde (SES) e a apoiadora Cosems-PR, além dos deputados, representantes do legislativo estadual. Já os atores de mercado são aqueles munidos de poder e que atuam de acordo com seus interesses econômicos, representados pelos prestadores privados e filantrópicos.

Enquanto os gestores municipais e estaduais concentram suas forças nas instâncias regionais, os prestadores privados e filantrópicos atuam induzindo diretamente as decisões governamentais em nível estadual. Além disto, são capazes de estabelecer estratégias para benefício próprio, fortalecendo seus privilégios como provedores de serviços no âmbito do SUS ${ }^{15}$.

De acordo com os participantes do estudo, entre os atores governamentais, o executivo municipal mostra forte atuação nas definições de políticas de saúde a serem implementadas na região. Este fato pode ser exemplificado nas aquisições de ASMC ambulatoriais pelo Consórcio Intermunicipal de Saúde (CIS) e na fala do entrevistado:

[...] para se contratar o serviço, tem que solicitar à presidência [do CIS] e à sua diretoria, que são as assembleias de prefeitos, e não de secretários. Então, a gente depende dos prefeitos para que se tomem decisões. (E6).

A influência dos prestadores hospitalares privados e filantrópicos também se destaca na governança das ASMC, pois eles têm capacidade de induzir os atores governamentais (deputados) na definição das ações e dos serviços de saúde ofertados à população, nem sempre considerando as necessidades e as demandas regionais.

Desse modo, nota-se que os atores de mercado realizam diferentes jogos, com vistas à manutenção da sua posição hegemônica, acarretando sérias complicações à governança dessa importante fração da assistência. Existe a predominância do jogo econômico, no qual o setor privado, representado pelos prestadores de serviço ao SUS, visa controlar os recursos econômicos e dominar o 'mercado' da atenção de ASMC na região.
A participação desse setor na saúde brasileira teve início mesmo antes da criação do SUS, com a compra de serviços médicos por empresas para garantir a assistência previdenciária de seus trabalhadores ${ }^{16}$. Após a criação do SUS, a lógica de compra de serviços de média e alta complexidade do setor privado ${ }^{17}$ não somente continuou, como foi considerada legal a complementariedade de serviços por esse setor. A dependência do setor privado para a oferta de serviços de média complexidade constitui um dos grandes desafios para a gestão das redes de atenção e regionalização dos territórios no SUS, incluindo a realização da governança no território ${ }^{\mathbf{7 7}}$.

Nota-se, também, a existência do jogo da comunicação, ao se verificar que os prestadores privados mostraram-se capazes de influenciar os atores governamentais, atravessando as arenas de negociação existentes na região, como a CIR e as pactuações do setor de planejamento da regional de saúde, inspirando as contratualizações de ASMC diretamente na Secretaria Estadual de Saúde. Soma-se, ainda, a esses jogos, o macro-organizacional, em que os prefeitos exercem seu poder institucional na relação com os demais entes, disputando a governança das ASMC, pela via do CIS na região.

Os resultados permitiram identificar que os atores representantes das comunidades profissionais e dos movimentos sociais podem ter uma frágil participação nos processos de governança, pois nem sequer foram citados, o que fragiliza as relações necessárias para que se consiga organizar a rede de atenção. Vale ressaltar que a governança permite a emergência de outras organizações e a capacidade de ação de vários atores, que não apenas os governamentais, mas também os não governamentais/informais ${ }^{3}$.

Quanto aos espaços para a articulação da governança, os participantes do estudo relataram, como possíveis arenas de negociação e pactuação: em âmbito regional, as reuniões do Conselho Regional de Secretários Municipais de Saúde (Cresems), da CIR, das Câmaras Técnicas, de avaliações do Programa de Apoio e Qualificação de Hospitais Públicos 
e Filantrópicos (Hospus) e do Programa de Apoio do Estado do Paraná aos Consórcios Municipais de Saúde (Comsus); e reuniões das assembléias de prefeitos, nas quais são discutidas questões pertinentes ao CIS. Na esfera estadual, foram citadas as reuniões do Cosems e as reuniões da Comissão Intergestores Bipartite (CIB). Já na instância federal, mencionou-se a Comissão Intergestores Tripartite (CIT).

Os entrevistados destacaram as reuniões das arenas regionais como espaços privilegiados para se pensar sobre a governança; entre esses, ressaltaram a do Cresems e da CIR, dando-se ainda maior ênfase às reuniões das CIR. As reuniões do Cresems acontecem mensalmente, algumas horas antes das reuniões da CIR. Participam destas, os secretários municipais de saúde, assessorados tecnicamente por meio da apoiadora do Cosems. Ocorrem frequentemente no prédio do município sede da regional de saúde, não havendo participação dos representantes da esfera estadual.

Já as reuniões da CIR acontecem na sede da regional de saúde, também com periodicidade mensal, ou podem ser realizadas extraordinariamente, quando necessário. Os participantes são os representantes da esfera estadual, os secretários municipais de saúde e a apoiadora do Cosems. Para um dos entrevistados:

[...] a CIR é o caminho para a realização da pactuação de soluções para a organização da rede regional de ações e serviços de atenção à saúde integrada e resolutiva, como no caso das ações e serviços de média complexidade. (E4).

Entretanto, as reuniões da CIR foram referidas como permeadas por atitudes centralizadoras da esfera estadual, ao manejarem as discussões, caracterizando um mero momento de aprovação de pautas predefinidas. Embora a CIR seja um espaço organizado há mais de duas décadas (antes denominado Colegiado de Gestão Regional), nota-se que ela não vem sendo utilizada para desempenhar seu papel conforme proposto, corroborando os dados encontrados em outros estudos, que apontam as reuniões de CIR como instâncias meramente burocráticas e homologatórias, não respondendo ao papel de ser um espaço legítimo de auxílio à gestão eficiente do SUS ${ }^{18,19}$.

Importa salientar a ausência de muitos gestores municipais nessas reuniões, e, ainda, o fato de que muitos dos que participam não se sentem capacitados para discutir temas relacionados à gestão e a políticas de saúde. A fragilidade no acúmulo de conhecimento demonstrado pelos gestores municipais influencia em sua capacidade de combinar jogadas sociais e dificulta sua interação com outros pares. Neste aspecto, a limitação na produção de jogadas inviabiliza a transformação das regras organizacionais nas instâncias regionais ${ }^{13}$.

A ausência dos gestores nas reuniões diminui sua capacidade na aquisição de estratégias para modificar as regras existentes nos espaços decisórios. Moreira, Ribeiro e Ouverney ${ }^{20}$ corroboram tal achado ao caracterizarem os ambientes de tomada de decisão como complexos, e que os atores participantes são detentores de racionalidade limitada, com capacidades fragilizadas para estabelecer seus próprios interesses e para compreender os dos demais.

Os entrevistados referiram que os sujeitos desses espaços agem muitas vezes por intuição, ou ainda, por 'consenso' com seus outros pares. Este fato causa prejuízos à governança exercida por tais atores, evidenciados na fala de um dos participantes do estudo:

[...] os secretários são muito mal preparados. Alguns nem são da área de saúde, outros não têm preparo de gestão. A gente sente uma dificuldade muito grande quando tem que discutir com os parceiros, de conseguir discutir. A gente sabe que tem problemas, dificuldade de resolver. A falta de resolutividade dos municípios é muito grande porque é um grupo onde não tem o embasamento total entre todos os seus entes. (E6).

Ao manifestar-se dessa forma, esses atores ocultam conflitos, não discutindo seus problemas, nem sua cadeia causal, o que impossibilita fundamentar suas ações, empobrecendo 
seu poder de decisão ${ }^{\mathbf{1 3}}$. Para Cortes ${ }^{\mathbf{1 5}}$, a ação articulada dos atores seria de fundamental importância para reestruturar as regras e o formato dos espaços decisórios.

Por tradição, o consensualismo é um termo atrelado ao federalismo, que vem ganhando destaque no perfil contemporâneo da administração pública9. Neste contexto, cabe destacar que o conceito de consenso muitas vezes é empregado de maneira inadequada, como sinônimo de unanimidade. Entretanto, torna-se necessário o desacordo, para que se chegue ao consenso de forma natural, não como temor de coerção.

Os resultados também demonstraram que as pactuações nessas arenas, muitas vezes são direcionadas pelo interesse de um dos entes ou de grupos que se encontram no poder, conforme expressa a fala:

[...] as redes é a proposta do governo do estado, desde a campanha da primeira eleição, da segunda eleição. A secretaria do estado de saúde nunca escondeu seus caminhos, que é a rede [...]. $O$ que eu digo é que os municípios se deixam pautar pela pauta do estado. [...] os municípios é que não conseguem ter o papel de também colocar as coisas a serem discutidas. (E6).

E, ainda nas arenas, os conflitos são poucos, de acordo com participante do estudo:

[...] não é um conflito de ideias. Porque não tem ideia, eles só têm o problema. A sugestão não chega, ou, se chega, é sugestão ilegal, sem base constitucional, sem base de estrutura, que não dá nem para discutir. (E6).

Para os entrevistados, quando existem opiniões divergentes entre os participantes nos processos de negociação, ocorre a convocação da câmara técnica, especificamente para se conversar sobre a área do conflito. Um dos participantes define a câmara, conforme a fala: "[...] essa câmara bipartite vista como meio para chegar a um consenso, para chegar um entendimento comum" (E5).
A câmara tem, por objetivo, ampliar a capacidade de debate e facilitar a decisão desses atores nas reuniões de CIR, porém essas câmaras não têm periodicidade estabelecida. Além disto, a falta de participação de alguns gestores nas arenas de articulação, somada à indefinição de prazo para a realização de câmaras técnicas, fragiliza o poderio processual técnico-político dos atores participantes destes espaços, bem como sua capacidade analítica, contribuindo para a incipiente governança das ASMC na região.

Destaca-se, entre os elementos-chave da governança voltada para a consolidação do SUS, a criação de um ambiente institucional favorável à coordenação e articulação de atores, serviços e ações em prol da universalização nas regiões de saúde ${ }^{4}$. Tais relações acontecem por meio de espaços denominados arenas, os quais são decisivos para a construção de uma política ${ }^{\mathbf{2 1}}$.

\section{Desafios enfrentados na região para governança das ASMC}

Entre os desafios revelados pelas falas dos participantes, estão: a falta de solidariedade e compartilhamento de responsabilidades entre os entes federativos; a fragilidade do ente municipal em relação aos demais atores envolvidos na governança (União, ente estadual e atores de mercado); o subfinanciamento do SUS, por parte das instâncias federal e estadual; a não efetivação do Contrato Organizativo da Ação Pública (Coap) na região; as fragilidades no sistema de regulação, nas esferas municipal e estadual; a interferência política de deputados junto ao Gestor Estadual, a favor dos grandes prestadores privados.

Para um dos entrevistados, as relações entre os entes federativos brasileiros têm sido um grande desafio para a governança das ASMC, de acordo com a fala de um dos participantes do estudo:

[...] o atual modelo é extremamente centralizador, com alta concentração de poderes, o que estimula a competição entre os entes, culminando com desnivelamento de repartição de poderes e recursos financeiros. (E4). 
Desse modo, torna-se difícil o fortalecimento da autonomia e da solidariedade entre os entes. Os entrevistados compreendem a governança como o compartilhamento solidário das ações em saúde, entre as instâncias governamentais, conforme a fala:

\section{[...] governança é compreendida como o compar-} tilhamento das responsabilidades e ações entre os entes federados (União, estados e municípios) na organização, planejamento e execução das funções de interesse comum. (E4).

Além disso, características sociais e demográficas diferenciadas, dos municípios que compõem a região, dificultam a interdependência e a solidariedade entre as instâncias subnacionais. A fala abaixo expressa esta ideia:

[...] então, 2 municípios veem as coisas de uma forma e 15 veem de outra, o que dificulta que [...] as vantagens sejam as mesmas para todos. Eu acho que, como a maioria são pequenos, a gente perde força. (E6).

Em um país heterogêneo como o Brasil, políticas públicas mal adaptadas às realidades regionais causam problemas, principalmente às camadas mais pobres da população ${ }^{22}$. Neste contexto, cabe frisar que a Constituição Federal de 1988 traz a assistência em saúde como responsabilidade concorrente dos municípios, Distrito Federal, estados e União. Abrucio e Franzese ${ }^{23}$ chamam a atenção para a grande parcela dos encargos que ficaram sob a responsabilidade dos municípios, assumida de forma desorganizada. Além disto, há a ausência de cooperação entre os outros entes federativos e o aumento de competição entre as instâncias subnacionais.

Esse cenário se torna ainda mais desafiador para os Municípios de Pequeno Porte (MPP), aqueles com população inferior a 20 mil habitantes ${ }^{24}$, pois a maioria deles não arrecada o suficiente para suprir suas despesas com a estrutura administrativa e legislativa ${ }^{25}$, possui baixa capacidade instalada de serviços no seu território, tornando-se dependentes dos municípios maiores da região, para acesso às $\mathrm{ASMC}^{26}$. Isto acarreta dificuldades aos MPP, para serem protagonistas no processo de governança das ASMC. Devido ao baixo poder político e econômico conferido a estes municípios, em muitos momentos, eles acabam se portando de forma subserviente aos municípios maiores, às outras instâncias federativas e aos prestadores privados.

Tal fato foi confirmado na região, onde $90 \%$ dos municípios são MPP e não apresentam recursos financeiros e administrativos suficientes, ou mesmo apoio político forte o bastante para a adoção de estratégias capazes de superar os obstáculos para alcançar a integralidade à saúde, nos três níveis de atenção.

Pinafo ${ }^{27}$ alia o baixo poder político dos MPP ao seu baixo contingente populacional, o que lhes acarreta uma menor quantidade de votos e dificulta a eleição de seus próprios representantes políticos. Quanto ao poder econômico, apesar destes municípios serem reconhecidos em sua autonomia, não possuem autossuficiência fiscal e tributária, gerando fragilidades em sua capacidade técnica de gestão.

Outro desafio referido foi o subfinanciamento do SUS, por parte das instâncias federal e estadual, para a aquisição de serviços ambulatoriais de média complexidade na região. Segundo o relato de um entrevistado, percebe-se maior investimento em saúde, por parte dos municípios, expresso na fala: "[...] as despesas do consórcio no ano de 2016, verificou-se que $71 \%$ dos recursos vieram dos municípios, $20 \%$ do governo federal e $9 \%$ do estado" (E8).

Esse cenário de maior participação do ente municipal no financiamento em saúde, em relação aos outros entes, também foi demonstrado em estudo feito pelo Conselho Federal de Medicina ${ }^{\mathbf{2}}$, no período compreendido entre 2008 e 2015 , em que as despesas dos governos federal e estaduais, com saúde, cresceram $40,4 \%$ e $49,4 \%$, respectivamente, enquanto nos municípios esse aumento correspondeu a $71,6 \%$. 
A governança das ASMC está diretamente relacionada ao financiamento, sendo viabilizada por meio dos planos de ação regionais, que devem detalhar os recursos financeiros, a responsabilidade de cada ente na sustentabilidade dos planos e os recursos que serão alocados pelo prestador de saúde ${ }^{29}$.

Nesse sentido, a governança das ASMC na região estudada tem se mostrado um processo bastante complexo, devido à dificuldade apresentada pelos entes quanto à clareza de suas competências, responsabilidades, direitos e deveres para sua participação na organização e integração das ações e serviços de saúde. E, apesar de comprometer uma parcela cada vez maior de seus orçamentos com a área da saúde, especialmente com ASMC, o ente municipal não domina o jogo macro-organizacional, não conseguindo materializar a produção institucional para o estabelecimento da governança dessa área.

Também se destacou, entre as fragilidades referidas para o fortalecimento da governança das ASMC, a não efetivação do Coap na região, acarretando uma grande barreira a ser transposta. O Coap constitui um instrumento para estabelecer as competências dos entes governamentais, além de auxiliar no processo de governança das ações e serviços de saúde disponibilizados pelo SUS na região ${ }^{30}$.

Para que esse contrato seja firmado, nota-se a necessidade de um processo de planejamento ascendente, locorregional, além da negociação entre os entes federados regionais, bem como a definição dos diversos compromissos a serem assumidos por estes atores com vistas a uma oferta de ações e serviços de saúde regionalizada e hierarquizada, que atendam às necessidades de saúde da população. Isto sem falar na definição das suas fontes de financiamento ${ }^{30}$.

Percebe-se que, passados mais de sete anos da publicação do Decreto $n^{0} 7.508 / 11^{30}$, apenas três estados brasileiros (Ceará, Mato Grosso e Alagoas) assinaram o Coap, segundo Feliciello ${ }^{31}$, o que demonstra a estagnação dessas discussões no sentido de implantar esse contrato.

O planejamento locoascendente integrado e participativo foi citado pelos entrevistados como um importante instrumento para a definição das necessidades e prioridades de saúde na região, como se vê na fala abaixo:

[...] eu entendo que a governança interfederati$v a$, ela começa desde a governança microrregional; tem um papel de fortalecimento de gestão regional, de microrregião, de estado e de governo federal. Eu entendo que essa governança interfederativa, você tem que começar com o planejamento locoascendente. (E1).

A não realização do planejamento ascendente também pareceu refletir nas formas de contratualizações hospitalares de ASMC na região, uma vez que os contratos e convênios foram celebrados de maneira centralizada na SES, geralmente de forma padronizada, nem sempre atendendo às necessidades apresentadas pela região.

Outro desafio referido foram as fragilidades no sistema de regulação, nas esferas municipal e estadual, gerando transtornos à eficiência do SUS, uma vez que a regulação concentra atividades de regulamentação, fiscalização, controle, auditoria e avaliação dos prestadores sobre a distribuição de ações e serviços de saúde. A macrorregulação deveria ser uma ação básica desenvolvida pela equipe gestora, possibilitando a defesa dos interesses coletivos.

$\mathrm{O}$ incipiente processo de planejamento ascendente e locorregional e a falta de regulação, aliada à insuficiente oferta de ASMC contratualizadas pelo ente estadual, referidos pelos participantes, têm como consequência a busca de uma alternativa pelo ente municipal, que corresponde às contratualizações paralelas e individuais junto aos prestadores privados. Estas contratualizações fragilizam o fortalecimento das políticas públicas de saúde, não atendendo aos interesses regionais. Isto é expresso na fala de um dos gestores:

[...] dificulta bastante, porque você luta pelos caminhos comuns para todos, você pensa no coletivo e não no individual. Aí, vai um município 
lá e paga para um prestador, que já é SUS, num contrato paralelo. (E3).

Essa forma de contratualização acontece à revelia das normativas do SUS, fere a lógica do comando único e fragiliza o controle e a fiscalização desses serviços, ao não respeitar os princípios gerais do sistema, além de criar um problema a longo prazo para a aquisição de ações e serviços de saúde na região ${ }^{\mathbf{3 1}}$. Neste sentido, o gestor público municipal, ao tentar resolver um problema, cria outro, que se manifestará mais adiante, ou seja, está realizando um intercâmbio de problemas ${ }^{\mathbf{1 3}}$.

Porém, nota-se que essas formas de acordo para acessar aos serviços de saúde nem sempre ocorrem por ingenuidade dos gestores, de acordo com a fala abaixo:

[...] eu não sei se eles não conseguem enxergar, ou se não fazem questão de enxergar [...] porque, se eu faço separado, eu consigo vaga na frente. Então, eu não sei até que ponto eles querem ou não querem, por interesse próprio, e isso dificulta a governança. (E1).

Ademais, a forma de contratualização de ações e serviços de saúde hoje vigente no SUS possibilita aos prestadores privados e filantrópicos sugestionarem as ASMC, haja vista a maior oferta ao SUS de ações e serviços de saúde que são mais rentáveis economicamente aos prestadores, e não necessariamente que seriam necessidades da região, o que foi evidenciado nos resultados.

Um outro desafio se deve à interferência política de deputados junto ao Gestor Estadual, em prol dos grandes prestadores privados, de acordo com o entrevistado: "[...] nesse sentido, a questão politica, todos os hospitais grandes têm muitos deputados por trás" (E1). Essa situação foi identificada como uma dificuldade para a efetivação da governança das ASMC. Sobre esse aspecto, foi uniforme a visão de que a política partidária tem sido um desafio a ser vencido para a instituição da governança das ASMC hospitalares, pois o protecionismo político, exercido por atores governamentais do poder legislativo estadual, resulta no sentimento de impotência e comodismo dos gestores municipais frente aos problemas encontrados junto aos prestadores de serviço, característica evidenciada na fala abaixo:

[...] o que eu acho que dificulta é a política. Tem hospitais que são protegidos politicamente e não adianta bater, porque é dar murro em ponta de faca, é briga de gente grande. Então, essa é a nossa maior dificuldade. (E7).

Essa situação gera sujeição dos gestores municipais de saúde aos prestadores. É oportuno destacar que a política partidária, muitas vezes, interfere negativamente nas políticas públicas de saúde ${ }^{32}$. O ente estadual, detentor do poder macro-organizacional, não o utiliza para produzir uma ação organizacional, em favor da governança das ASMC, permitindo que o poder econômico dos prestadores privados prevaleça. Para Matus ${ }^{13}$, o poder político, ao subordinar-se ao poder econômico das minorias (prestadores), permite o jogo plutocrático, no qual o poder é exercido pelos grupos mais ricos. Neste contexto, merece crítica a ineficiência do Estado Brasileiro (União, estados e municípios) para frear os interesses das minorias, em detrimento aos da coletividade.

\section{Considerações finais}

O processo de governança das ASMC se constitui em um grande jogo, complexo, permeado por relações sociais de competição e conflitos entre os atores participantes (governamentais e de mercado), que sofre forte influência do jogo econômico. Apesar de a CIR se constituir em um espaço privilegiado, ela não foi suficiente para que governança das ASMC se efetivasse na região estudada.

Vários desafios necessitam ser enfrentados, então, para que o processo de governança se efetive, entre eles: a necessidade de relações 
mais simétricas e solidárias entre os entes federados; o fortalecimento da participação social e das comunidades profissionais, bem como da qualificação dos gestores municipais de saúde para o processo de negociação com outros atores; a garantia de financiamento SUS suficiente às necessidades da área da ASMC; a implantação de sistemas de regulação que garantam a oferta e o acesso adequado, em tempo oportuno, dos cidadãos às ASMC, atendendo às necessidades da população, e não aos interesses de prestadores privados.

Em um cenário de mudanças nas legislações, em especial no que tange ao financiamento das políticas públicas, à (des)regulamentação da participação do setor privado na saúde, à flexibilização da aplicação dos recursos dos SUS pelos gestores, recomenda-se a realização de estudos que analisem o impacto destas mudanças na área da ASMC, principalmente nas relações entre atores e na governança da área.

\section{Colaboradores}

Domingos CM (0000-0002-7725-1831)*, Ferraz EM (0000-0002-7721-7529)* e Carvalho BG (0000-0003-3850-870X)* contribuíram igualmente na elaboração do manuscrito.

\section{Referências}

1. Fleury S, Ouverney AM. Gestão de redes: a estratégia de regionalização da política de saúde. Rio de Janeiro: Editora FGV, 2007.

2. Pinheiro R, Peres AMAM, Velloso G, et al. Apoio regional no estado do Rio de Janeiro, Brasil: um relato de experiência. Interface (Botucatu) [internet]. 2014 [acesso em 2018 set 5]; 18(supl1):1125-1133. Disponível em: http://dx.doi.org/10.1590/1807-57622013.0375.

3. Marques EC. Government, political actors and governance in urban policies in Brazil and São Paulo: concepts for a future research agenda. Bras. Political Sci. Rev. (São Paulo). 2013; 7(3):8-35.

4. Lima LD, Albuquerque MV, Scatena JHG. Quem go- verna e como se governam as regiões e redes de atenção à saúde no Brasil? Contribuições para o estudo da governança regional na saúde [internet]. (Novos Caminhos, n. 8). [acesso em 2019 jun10]. Disponível em: http://www.resbr.net.br/wp-content/uploads/2016/02/Novos-Caminhos-8.pdf.

5. Silva CR, Carvalho BG, Cordoni Júnior L, et al. Dificuldade de acesso a serviços de média complexidade em municípios de pequeno porte: um estudo de caso. Ciênc. Saúde Colet. 2017; 22(4):1109-1120.

6. Brasil. Ministério da Saúde. O SUS de A a Z: garantindo saúde nos municípios/Ministério da Saúde, Conselho Nacional de Secretarias Municipais de Saúde. 3. ed. Brasília, DF: Ministério da Saúde; 2009.
*Orcid (Open Researcher and Contributor ID). 
7. Ribeiro PT, Tanaka OY, Denis JL. Governança regional no Sistema Único de Saúde: um ensaio conceitual. Ciênc. Saúde Colet. 2017; 22(4):1075-1084.

8. Nicoletto SCS. As Comissões Intergestoras Regionais e a Gestão Interfederativa no Norte do NN, 2011 a 2013. [tese] Londrina: Universidade Estadual de Londrina; 2015.

9. Dourado DA, Elias PE. Regionalização e dinâmica política do federalismo sanitário brasileiro. Rev. Saúde Pública, 2011, 45(1):204-211.

10. Abrucio FL. A coordenação federativa no Brasil: a experiência do período FHC e os desafios do governo Lula. Rev. Soc. Polít. 2005; (24):41-67.

11. Santos L, Andrade LOM. Redes interfederativas de saúde: um desafio para o SUS nos seus vinte anos. Ciênc. Saúde Colet. 2011; 16(3):1671-1680.

12. Martins J, Bicudo MAV. A pesquisa qualitativa em psicologia: fundamentos e recursos básicos. São Paulo: Centauro; 2005

13. Matus C. Teoria do jogo social. Tradução Luís Felipe Rodriguez Del Riego; revisão técnica Vanya Mundim Sant’Ana. São Paulo: Fundap; 2005.

14. Brasil. Ministério da Saúde. Conselho Nacional de Saúde. Resolução nº 466/12 de 12 de dezembro de 2012. Aprova as diretrizes e normas regulamentadoras de pesquisas envolvendo seres humanos. Brasília, DF. Diário Oficial da União. 13 Dez 2012.

15. Côrtes SV. Sistema Único de Saúde: espaços decisórios e a arena política de saúde. Cad. Saúde Pública. 2009, 25(7):1626-1633.

16. Menicucci TMG. Público e privado na política de assistência à saúde no Brasil: atores, processos e trajetória [tese]. Belo Horizonte: Universidade Federal de Minas Gerais; 2003.

17. Romano CMC, Scatena JHG, Kehrig RT. Articulação público-privada na atenção ambulatorial de média e alta complexidade do SUS: atuação da Secreta- ria de Estado de Saúde de Mato Grosso. Physis 2015; 25(2):1095-1115.

18. Ianni AMZ, Monteiro PHN, Alves OSF, et al. Metrópole e região: dilemas da pactuação da saúde. O caso da Região Metropolitana da Baixada Santista, São Paulo, Brasil. Cad. Saúde Pública. 2012; 28(5):925-934.

19. Mota PHS, Viana ALA, Bousquat A. Relações federativas no Programa Academia da Saúde: estudo de dois municípios paulistas. Saúde debate. 2016; 40(108):6473.

20. Moreira MR, Ribeiro JM, Ouverney AM. Obstáculos políticos à regionalização do SUS: percepções dos secretários municipais de Saúde com assento nas Comissões Intergestores Bipartites. Ciênc. Saúde Colet. 2017; 22(4):1097-1108.

21. Fleury S, Ouverney AM. Política de saúde: uma política Social. In: Giovanella L, Escorel S, Lobato LVC, et al. Políticas e sistema de saúde no Brasil. Rio de Janeiro: Fiocruz; 2012.

22. Cavalheiro ME, Juchem DM. Políticas Públicas: Uma analise mais apurada sobre Governança e Governabilidade. Revista Brasileira de História e Ciências Sociais. 2009; 1(1):1-11.

23. Abrucio F, Franzese C. Federalismo e políticas públicas: o impacto das relações intergovernamentais no Brasil. In: Araújo M, Beira L, organizadores. Tópicos da Economia Paulista para Gestores Públicos. São Paulo: Fundap; 2007, p. 13-31.

24. Brasil. Ministério do Desenvolvimento Social e Combate à Fome e Secretaria Nacional de Assistência Social. Política Nacional de Assistência Social PNAS/2004. Brasília, DF: Ministério da Saúde; 2005.

25. Arcari JM, Barros APD, Rosa RS, et al. Perfil do gestor e práticas de gestão municipal no sistema único de Saúde (SUS) de acordo com porte populacional nos municípios do estado do Rio Grande do Sul. Ciênc. Saúde Colet. 2018 [acesso em 2019 maio 5]. Disponível em: http://www.cienciaesaudecoletiva. com.br/artigos/perfil-do-gestor-e-praticas-de-ges- 
tao-municipal-no-sistema-unico-de-saude-sus-de-acordo-com-porte-populacional-nos-municipios-do-estado-do-rio-grande-do-sul/16876.

26. Silva JFM, Carvalho BG, Domingos CM. A governança e a relação público-privado no cotidiano das práticas em municípios de pequeno porte. Ciênc. Saúde Colet. 2018; 23(10):3179-3188.

27. Pinafo E. Problemas e estratégias de gestão do SUS em municípios de pequeno porte. [tese]. Londrina: Universidade Estadual de Londrina; 2017.

28. Conselho Federal de Medicina. A participação federal no SUS diminui. Jornal Medicina. 2015 [acesso em 2019 maio 5]; 245:1-12. Disponível em: http:// www.flip3d.com.br/web/pub/cfm/?numero=245.

29. Brasil. Ministério da Saúde. Secretaria de Atenção à Saúde. Implantação das Redes de Atenção à Saúde e outras estratégias da SAS/Secretaria de Atenção à Saúde. Brasília, DF: Ministério da Saúde, 2014.
30. Brasil. Presidência da República Decreto $n^{\circ} 7.508$, de 28 de junho de 2011. Regulamenta a Lei no 8.080, de 19 de setembro de 1990. Diário Oficial da União. 29 Jun 2011.

31. Feliciello D, Oliveira JCR, Vilalba JP, et al. Contratualização de Serviços de Saúde. Guia Prático para Gestores Públicos. Campinas: Unicamp/NEPP/AGEMCAMP; 2016.

32. Carvalho LB, Jesus WLA, Senra IMVL. Regionalização no SUS: processo de implementação, desafios e perspectivas na visão crítica de gestores do sistema. Ciênc. Saúde Colet. 2017; 22(4):1155-1164.

Recebido em 03/12/2018

Aprovado em 25/05/2019

Conflito de interesses: inexistente

Suporte financeiro: não houve 